\title{
The job demands-resources model of work engagement in South African call centres
}

\author{
Authors: \\ Yolandi Janse van Rensburg ${ }^{1}$ \\ Billy Boonzaier ${ }^{1}$ \\ Michèle Boonzaier ${ }^{1}$ \\ Affiliations: \\ ${ }^{1}$ Department of Industrial \\ Psychology, Stellenbosch \\ University, South Africa \\ Correspondence to: \\ Billy Boonzaier \\ Email: \\ bb@sun.ac.za \\ Postal address: \\ Department of Industrial \\ Psychology, Stellenbosch \\ University, Private Bag X1, \\ Matieland 7602, South Africa \\ Dates: \\ Received: 05 July 2012 \\ Accepted: 08 July 2013 \\ Published: 30 Sept. 2013 \\ How to cite this article: \\ Janse van Rensburg, Y., \\ Boonzaier, B., \& Boonzaier, \\ M. (2013). The job demands- \\ resources model of work \\ engagement in South \\ African call centres. $S A$ \\ Journal of Human Resource \\ Management/SA Tydskrif vir \\ Menslikehulpbronbestuur, \\ 11(1), Art. \#484, 13 pages. \\ http://dx.doi.org/10.4102/ \\ sajhrm.v11i1.484

\section{Copyright:} \\ (C) 2013. The Authors. \\ Licensee: AOSIS \\ OpenJournals. This work \\ is licensed under the \\ Creative Commons \\ Attribution License.
}

Read online:

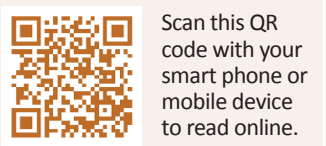

Orientation: A 'sacrificial human resource strategy' is practised in call centres, resulting in poor employee occupational health. Consequently, questions are posed in terms of the consequences of call centre work and which salient antecedent variables impact the engagement and wellbeing of call centre representatives.

Research purpose: Firstly, to gauge the level of employee engagement amongst a sample of call centre representatives in South Africa and, secondly, to track the paths through which salient personal and job resources affect this engagement. More specifically, the relationships between sense of coherence, leadership effectiveness, team effectiveness and engagement were investigated, thus testing the Job Demands-Resources model of work engagement.

Motivation for the study: To present an application of the Job Demands-Resources model of work engagement in a call centre environment in order to diagnose current ills and consequently propose remedies.

Research design: A cross-sectional survey design was used and a non-probability convenient sample of 217 call centre representatives was selected. The measuring instruments comprise the Utrecht Work Engagement Scale to measure engagement, the Team Diagnostic Survey to measure team effectiveness, the leadership practices inventory to gauge leadership effectiveness, and the Orientation to Life Questionnaire to measure sense of coherence. A series of structural equation modelling analyses were performed.

Main findings: Contrary to the 'electronic sweatshop' image attached to call centre jobs depicted in the literature, results show a high level of employee engagement for call centre representatives in the sample. Also, personal resources such as sense of coherence and job resources such as team effectiveness related significantly to engagement. A non-significant relationship exists between leadership effectiveness and engagement.

Practical/managerial implications: Both the content and context of jobs need to be addressed to increase the personal and job resources of call centre representatives.

Contribution/value-add: The Job Demands-Resources model of work engagement can be used to improve the occupational health and performance of employees in call centres.

\section{Introduction}

\section{The nature of call centres}

The call centre industry in South Africa consists of approximately 1500 call centres and currently employs approximately 150000 call centre representatives (CCRs) (Banks \& Roodt, 2011). A call centre is defined by Holman (2005, p. 111) as 'a work environment in which the main business is mediated by a computer and telephone based technologies that enable the efficient distribution of incoming calls (or allocation of outgoing calls) to available staff, and permit the customeremployee interaction to occur simultaneously with the use of display screen equipment and the instant access to, and inputting of, information. It includes parts of companies dedicated to this activity, as well as whole companies that specialize in such services'. Inbound call centres mainly respond to incoming calls and deal with customer complaints, requests and questions. Outbound call centres are mainly for initiating contacts on behalf of an organisation attempting to sell products or services. Call centres in general consist of jobs of different levels of complexity, ranging from unskilled CCRs who provide standard information from prescribed scripts to highly skilled representatives who deal with sophisticated problems as in the case of nursing or medical help desks.

Holman, Batt and Holtgrewe (2007) report the results of a global study of the management and employment practices in call centres. The survey included 475000 employees covering almost 2500 call centres in 17 countries. Data revealed that call centres look similar across countries 
with regard to organisational features, markets and service offerings. However, call centre workplaces differ based on the customs, norms and laws of the specific country. The average age of the call centres studied was eight years. The call centre industry evidenced certain general characteristics. Call centres typically serve national rather than international markets $(86 \%$ serve only their national, regional or local market). Two-thirds of all call centres serve the company's own customers. Inbound calls account for $78 \%$ of call traffic, similar technologies are employed and the average call lasts between 3 and $4 \mathrm{~min}$. Seventy five per cent of CCRs work in centres employing 230 or more workers. Structures are flat, with managers comprising $12 \%$ of staff. Females make up $71 \%$ of the staff complement.

In recently industrialised countries, performance monitoring (i.e. feedback on performance and call quality and listening) occurs on a weekly basis or more often. For example, a comprehensive oral performance evaluation instrument was developed to assess Filipino CCRs' customer service transactions with callers from the United States (Friginal, 2013). Ratings of job quality (using indices of employee discretion and supervisory monitoring) reveal that $50 \%$ of call centres in industrialised countries have low to very low quality jobs (low discretion or high monitoring). Internationally, this number drops to $38 \%$; India is a notable exception: $75 \%$ of call centres have low job discretion, and monitoring activities are the most intense of any country. A full $67 \%$ of all call centre workers in the world work in low to very low quality jobs. With regard to management practice, $60 \%$ of call centres make no use of self-directed teams; the exception is Sweden where $60 \%$ of the call centre workforce is involved in self-directed teams. The global average call centre staff turnover rate is $20 \%$ with great variation between countries (e.g. turnover in Austria is $4 \%$, whereas in India it is $40 \%$ and one-third of staff have less than one year's service at the call centre).

The first call centres in South Africa began to appear in the mid-1970s and mushroomed in the late 1990s due to a combination of improved computer technology and reduced telecommunications costs (Benner, Lewis \& Omar, 2007). South African call centres developed similarly to most other countries in that they emerged initially to serve a domestic market. South Africa, along with the rest of the world, experienced a call centre boom since the late 1990s. Call centres are increasingly being utilised by various government departments in South Africa to coordinate and facilitate communication between stakeholders during service delivery programmes (Bond-Barnard, Steyn \& Fabris-Rotelli, 2013). Gordi (2006) sums up several reasons why investors consider South Africa the ideal location for international call centres. A favourable exchange rate between the South African Rand and all major international currencies translates into a lower operational cost. South Africa is rich in the amount of skilled labour required and workers are equipped with a relatively neutral accent. The local telecommunications industry possesses advanced technologies with international cable and satellite links and shares a similar time zone with the European Union.

\section{Problems and research initiating questions}

A study of call centres in Gauteng by Fischer, Miller and Thatcher (in Banks \& Roodt, 2011) found that the management practices employed underscore Taylorism and a command-and-control approach. Currently the industrial psychology literature related to call centres highlights the negative aspects of call centre work environments and the resultant adverse impact on worker well-being. According to Rameshbabu, Reddy and Fleming (2013), the burgeoning call centre industry is characterised by long working hours, varying schedules and unique job demands, which render it susceptible to high absenteeism, high turnover and negative health outcomes.

Call centres have been labelled 'assembly lines in the head', 'electronic sweatshops' or 'satanic mills' (Armistead, Kiely, Hole \& Prescot, 2002). High stress levels, high staff turnover and emotional burnout are factors that are often associated with call centres (Lombard, 2009). The fairly low-skilled nature of the work in some call centres is associated with low levels of job satisfaction (Rose \& Wright, 2005). The jobs of CCRs are characterised by repetitive movements whilst complex information is technologically processed. However, good communication skills and efficiency are expected of CCRs. In addition, call centre employees often work in noisy environments under high time pressure, and their performance is usually monitored online (Ferreira \& Saldiva, 2002). Brannan (2005) describes call centre agents as emotional labourers. High emotional labour has been associated with a number of negative psychosocial effects. The reason for this is due to emotive dissonance and a clash between real feelings and a fake display of feelings (Tracy, 2005). Li, Chen and $\mathrm{Lu}$ (2008) report that musculoskeletal discomfort, a hoarse or painful throat and eye strain are the most prevalent work-related symptoms among CCRs. Inadequate sleep and job stress from interpersonal factors were associated with experienced cardiovascular and gastrointestinal symptoms (Rameshbabu, Reddy \& Fleming, 2013). Also, encountering difficult customers was shown to be the most pronounced stressor in a call centre.

Researchers have challenged the industry's 'sweatshop' image and called for the redesign of jobs in call centres (Boonzaier \& Boonzaier, 2008; Cartwright, 2003; Crome, 1998; Fisher, Milner \& Chandraprakash, 2007; Hauptfleisch \& Uys, 2006). In terms of management practice in call centres, it seems evident that managers are unwilling to compromise efficiency for quality customer service and CCRs' occupational well-being. Illhealth, disengagement, burnout and high absenteeism and turnover of employees are accepted as the norm and have been referred to as the 'sacrificial human resource strategy' of call centres by Wallace, Eagleson and Waldersee (2000, p. 174). Balance is lost between the logics of efficiency, customer care and the well-being of the employee. The CCR experiences the tension of the incompatibility between these goals and feels compelled to satisfy the demands of the company and the demands of customers, sometimes at the expense of personal need satisfaction. A series of related conflicts are experienced 
by CCRs: being treated as machines while supervisors tell them that they are valued, and managers espousing trust, but employing technology of distrust. For example, Baraka, Baraka and EL-Gamily (in press) developed qualitative metrics to maximise call centre efficiency and quality. In this instance the DeLone and McLean model was introduced in order to evaluate the performance of call centres. In South Africa, there is a lack of alignment between the mission statements of companies, which purport client satisfaction, and the performance targets the call centre managers propagate. Also, the use of readily available, technologically driven efficiency measures by call centre managers 'limits the variation in management practices that call centres can use' (Banks \& Roodt, 2011, p. 16).

The question arises whether above accusations are universal or not. Kinnie, Hutchinson and Purcell argue that:

... call centres exhibit fascinating contrasts between satisfying customer needs and motivating employees, between intensive surveillance systems and normative, fun activities, and between the demands of the product market and the pressures of the labour market (2000, p. 968).

There are call centres that have managed to balance conflicting pressures by incorporating fun-filled initiatives, and enhancing personal and job resources in an environment where employees are tightly constrained. For example, as CCRs spend up to $90 \%$ of their working day sitting, the use of sit-stand desks was associated with countering sedentary behaviour (Straker, Abbott, Heiden, Mathiassen \& Toomingas, 2013), which consequently has been shown to be a risk factor for obesity, diabetes, some cancers and even death. In a study of 339 Swiss call centre employees (Grebner, Semmer, Lo Faso, Gut, Kalin \& Elfering, 2003), CCRs were compared to five other occupations (cooks, sales assistants, nurses, bank clerks and electronics technicians). Similar levels of well-being and less intention to quit were found amongst CCRs compared to the other occupational groups:

Call centre work compares favourably with shop floor manufacturing and clerical work with regard to well-being. Indeed, at two call centres the level of well-being was equivalent to, and in many cases better than, these comparable forms of employment (Holman, 2002, p. 46).

Hart, Chiang and Tupochere (2009), in their Cape Town study, found a good balance between CCRs' drive for efficiency and customer care.

The call centre industry has started focusing on high commitment management or high involvement work systems to remedy current poor call centre people practices. High commitment management typically involves 'recommitment practices which aim to attract and select highly committed and flexible people, internal labour markets which reward commitment and training with promotion and job security, and methods of direct communication and team working' (Wood \& De Menezes, in Kinnie et al., 2000, p. 968). Much focus is placed on reviewing the management structure, modifying the reward or recognition systems and increasing flexibility by introducing training for staff.
Empirical studies by Schaufeli and Bakker (2004) have revealed that some employees, regardless of high job demands and long working hours, do not develop burnout. These members seem to find pleasure in hard work and dealing with job demands. In a study by Kinman and Jones (2003) it was found that some employees thrived on the fact that their work is stressful. Richardson and Hawcroft (in Banks \& Roodt, 2011) indicate that the nature of the work executed in call centres, as well as how they are managed, varies widely. They classified call centres as either dystopian or utopian. Dystopian call centres are characterised by high target setting, excessive surveillance, disengaged employees and constant monitoring. Utopian call centres, on the other hand, encourage and empower CCRs to engage with customers to meet their needs and grant CCRs flexibility and discretion in performing their work. Holman (2002) argues that, whereas some employees may enjoy call centre work, for many it is demanding, stressful, and promotes occupational ill health. The potential benefits of call centre work for employees, over and above their salary, are not clear.

In conclusion, the overriding detrimental effects of call centre work are well documented and the call centre industry is currently in a poor state with regard to management and people practices. The main research-initiating question for this study is therefore:

- Which salient antecedent variables in call centres impact the occupational well-being of CCRs in South Africa?

Tangential research-initiating questions are:

- What are the consequences of call centre work in terms of the occupational well-being of CCRs in South Africa?

- What is the road forward for management and people practices in call centres in South Africa?

\section{Call centres and the Job Demands-Resources model of work engagement}

The major challenge that the managers of call centres face is to find ways to engage employees and to build a sense of belonging and ownership that will support efficiency, customer satisfaction and CCR occupational health. The present study uses an overall theoretical framework of occupational well-being, the Job Demands-Resources (JD-R) model, reformulated by Bakker (2011), to examine how different categories of working conditions in call centres are related to work engagement and performance. Since its initial development by Demerouti, Bakker, Nachreiner and Schaufeli (2001), the JD-R model has demonstrated usefulness as a comprehensive yet parsimonious model for conceptualising and investigating well-being, engagement and work performance.

The JD-R model has been applied to various occupational settings, irrespective of the particular demands and resources involved. It has been tested locally by Rothmann and Joubert (2007) and internationally for various occupational groups (including teachers, hospital nurses, dentists, blue-collar and white-collar workers, and private home-care professionals), including call centre employees (Llorens, Bakker, Schaufeli 
\& Salanova, 2006). The basic structure of the JD-R model is maintained even when it is applied in different national and international contexts. The JD-R model assumes that job resources (e.g. autonomy, performance feedback, social support and supervisory coaching) and personal resources (e.g. optimism, self-efficacy, resilience and self-esteem), independently or in combination, predict worker engagement, especially when the job demands (e.g. work pressure, emotional demands and physical demands) are high, as in the case of call centre work. Job demands refer to the characteristics of the job that require sustained physical or psychological (cognitive and emotional) effort or skills and are associated with physiological or psychological costs. Job resources refer to those characteristics of the job that are functional in achieving work goals, reduce job demands and the associated physiological and psychological costs, or stimulate personal growth, learning and development (Bakker \& Demerouti, 2007).

Worker engagement, in turn, has a positive impact on job performance (e.g. in-role performance, creativity and financial turnover). Job and personal resources thus initiate a motivational process that leads to worker engagement and quality performance. The JD-R model of work engagement is graphically depicted in Figure 1. The feedback loop indicates how employees who are engaged and perform well are able to create their own resources that foster further engagement and better performance. This process of employees actively changing or influencing their work environments and job characteristics is referred to as job crafting. 'Job crafting is defined as the self-initiated changes that employees make in their own job demands and job resources to attain and/ or optimize their personal (work) goals' (Tims, Bakker \& Derks, 2012).

The JD-R model explains how employees' working conditions influence their health and commitment to the organisation through two independent processes. This model assumes that job resources and job demands evoke two different but related processes, namely a motivational process in which job resources stimulate employees' motivation to foster engagement and organisational commitment and, secondly, a health impairment process in which high job demands deplete employees' mental and physical resources leading to job burnout and health problems (Demerouti \& Bakker, 2011).

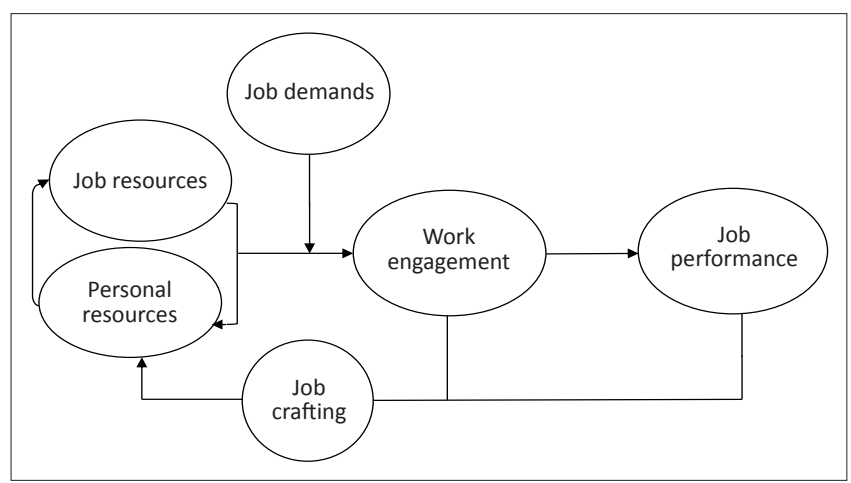

Source: Bakker, A.B. (2011). An evidence-based model of work engagement. Current Direction in Psychological Science, 20(4), 265-269

FIGURE 1: The job demands-resources model of work engagement.
The absence of personal and job resources evoke a cynical attitude towards work interactions. It is postulated that job resources may 'buffer the impact of job demands on job strain, including burnout' (Bakker \& Demerouti, 2007, p. 314). Bakker, Demerouti and Schaufeli stated that:

... call centre employees who can draw upon job resources such as social support from colleagues and performance feedback feel more dedicated to their work and more committed to their organization, and, consequently, are less inclined to leave the organization (2003, p. 408).

\section{Goals of the study}

Given the problems in call centres and given the JD-R model as a framework to understand and investigate this work engagement problem, the study set out, firstly, to gauge the level of employee engagement amongst a sample of call centre representatives (CCRs) in South Africa and, secondly, to track and thereafter test the hypothesised causal paths through which salient personal and job resources, as reported in the literature, affect the engagement of CCRs.

\section{What will follow}

Consequently, prominent studies and attendant hypotheses that relate to the goals of this investigation will be discussed. Also, the research approach and method, the results, a discussion of the findings and the recommendations for management practice in call centres will be presented.

\section{Literature review}

\section{Work engagement in call centres}

'Employee engagement is a desirable condition, has an organisational purpose, and connotes involvement, commitment, passion, enthusiasm, focused effort, and energy, so it has both attitudinal and behavioural components' (Macey \& Schneider, 2008, p. 4). Hence, engagement is of fundamental importance to any organisation's success. Huckerby (in Pech \& Slade, 2006) found that only 17\% of employees are truly engaged in their organisations, while $63 \%$ are not engaged and 20\% are disengaged (i.e. have uncoupled themselves from work roles and withdraw cognitively and emotionally). In research conducted by Tasker (in Pech \& Slade, 2006), 25\% of human resource organisations admitted that their staff were not engaged and that the situation was worsening. Almost half (44\%) said that tackling the issue was an overwhelming challenge.

Based on the aforementioned studies reporting the problems experienced in call centres and given the general lack of engagement in the workplace, the following question arose: What is the level of CCR work engagement in South Africa? Consequently, the following hypothesis was formulated:

- Hypothesis 1: A low level of work engagement exists amongst CCRs in South Africa.

Work engagement is defined by Kahn (1990, p. 694) as 'the harnessing of organisation members' selves to their work roles; in engagement, people employ and express themselves physically, cognitively and emotionally during 
role performances'. Engagement has been used to refer to a psychological state (involvement, commitment, attachment, mood), a performance construct (either effort or observable behaviour, including pro-social and organisational citizenship behaviour), disposition (positive affect), or some combination thereof (Macey \& Schneider, 2008). CCRs who are engaged become physically involved in tasks, are cognitively vigilant and become emphatically connected to others in the work that they are doing.

Work engagement is defined in terms of three dimensions, namely vigour, dedication and absorption (Schaufeli \& Bakker, 2003):

- Vigour is characterised by high levels of energy and mental resilience whilst working, as well as a willingness to exert effort and to persist even through difficult times. Thus, an employee who feels great vigour at work is highly motivated by their job and is likely to remain very persistent when encountering difficulties or hassles at work (Mauno, Kinnunen \& Ruokolainen, 2006).

- Dedication is characterised by a strong psychological involvement in one's work, feeling a sense of significance and enthusiasm, inspired and proud, and viewing work as a challenge. This dimension of work engagement shares some conceptual similarity with the more traditional concept of job involvement, which has been defined as the degree to which an employee psychologically relates to their job and to the work performed therein (Mauno et al., 2006). Vigour and dedication are the direct opposites of (emotional) exhaustion and mental distance (depersonalisation), when considering burnout (Schaufeli \& Bakker, 2003).

- Absorption refers to 'total concentration on immersion in work characterized by time passing quickly and finding it difficult to detach oneself from one's work' (Schaufeli, in Mauno et al., 2006, p. 151). Absorption is closely related to the concept of 'flow' (Nakamura \& Csikszentmihalyi, in Van der Colff \& Rothmann, 2009), an optimal state of experience where focused attention, a clear mind, unison of body and mind, effortless concentration, complete control and intrinsic enjoyment are experienced. People get so intensely involved in an activity that nothing else seems to matter; the experience itself is so enjoyable that people will do it even at a great cost, purely for the sake of doing it (Mauno et al., 2006).

Work engagement helps individuals to derive benefits from stressful work (Britt, Adler \& Bartone, in Sonnetag, 2003). Bakker, Demerouti, Hakanen and Xanthopoulou (2007) found that work engagement is positively related to organisational commitment and business unit performance (customer satisfaction, loyalty, profitability, productivity, turnover and safety). Engaged workers tend to work harder and are more likely to produce the results their customers and organisations want. Engaged workers have high energy and self-efficacy (Schaufeli, in Bakker \& Demerouti, 2008) and report that their jobs make good use of their skills, that their work is challenging and stimulating, and that their work provides them with a sense of personal accomplishment (Roberts \& Davenport, 2002).
Engaged workers are more productive than non-engaged workers; they experience positive emotions and better health (Bakker \& Xanthopoulou, 2013), create their own job and personal resources, and transfer their engagement to others. It is conceivable that the transfer of engagement amongst members of the same work team increases performance. 'If colleagues influence each other with their work engagement, they may perform better as a team' (Bakker \& Demerouti, 2008, p. 217). Engaged employees are successful in mobilising their job resources (Schaufeli \& Bakker, 2003), hence a team of engaged workers is more likely to have the resources they need for effective performance, in contrast with a team of disengaged workers. Based on this evidence, the following hypothesis was formulated:

- Hypothesis 2: Work engagement has a significant positive effect on team effectiveness (TE).

\section{Sense of coherence: A critical personal resource in call centres}

Muller and Rothmann (2009) identify sense of coherence as a critical personal resource associated with coping with stress. Antonovsky gives the following definition of SOC:

The sense of coherence is a global orientation that expresses the extent to which one has a pervasive, enduring though dynamic feeling of confidence that the stimuli deriving from one's internal and external environments in the course of living are structured, predictable, and explicable; the resources are available to one to meet the demands posed by these stimuli; and these demands are challenges, worthy of investment and engagement. (Antonovsky, 1993)

Sense of coherence consists of three components: comprehensibility, manageability and meaningfulness. Fourie, Rothmann and Van de Vijver (2008) describe these concepts in the following way:

- Comprehensibility refers to the extent to which one perceives stimuli from the internal and external environment as information that is ordered, structured and consistent. The stimuli are perceived as comprehensible and make sense on a cognitive level.

- Manageability refers to the extent to which individuals experience events in life as situations that are endurable or manageable, or even as new challenges.

- Meaningfulness refers to the extent to which one feels that life is making sense on an emotional and not just a cognitive level.

In a study undertaken to investigate the effects of job demands, job resources and sense of coherence on the burnout and work engagement of non-professional counsellors in South African banks, it was found that non-professional counsellors with a strong sense of coherence experienced less burnout and more work engagement. Presumably, this is because stimuli from the environment are perceived as 'making cognitive sense' and as 'motivationally relevant and meaningful' (Fourie et al., 2008, p. 44). Muller and Rothmann (2009) also report a positive relationship between SOC and job satisfaction, work engagement, life satisfaction, general well-being and actively coping with stressors. Hence, based on the above-mentioned evidence, a third hypothesis was formulated: 
- Hypothesis 3: Sense of coherence of CCRs has a significant positive influence on work engagement.

Individuals who have a high SOC usually exhibit resistance to the effects of stress and are more capable of encountering stressful situations without experiencing the negative effects thereof. These people tend to experience environmental stimuli in a manner sufficiently structured to enable them to anticipate events and the resources required to meet the demands imposed on them. Such experiences are likely to lead to favourable perceptions of one's own influence at work and the support that one receives from supervisors and colleagues (Fourie et al., 2008). Employees with a weak SOC tend not to be particularly satisfied with or passionate about their jobs. Employees with a strong SOC search for meaning in life; consequently they also expect it from challenging assignments in their work and are keen to join groups where a variety of skills is required. Rothmann (in Muller \& Rothmann, 2009) found SOC to be significantly related to job satisfaction. Workers with a high SOC experience a positive relationship with colleagues and management, and receive recognition with a higher frequency compared to those with a weak SOC (Rothmann, in Muller \& Rothmann, 2009). Given that SOC influences the ability to mobilise and generate social resources in the workplace (Fourie et al., 2008) and that optimal individual contributions set the scene for effective teamwork (Mickan \& Rodger, 2002), it can be inferred that a team consisting of members with a high SOC may demonstrate greater team effectiveness. Based on the aforementioned studies, the following hypothesis was formulated:

- Hypothesis 4: CCRs' sense of coherence has a significant positive effect on team effectiveness.

\section{Team effectiveness: A critical job resource in call centres}

Salanova, Llorens, Cifre, Martinez and Schaufeli (2003) consider the perceived collective efficacy of members of a work team as an important job resource impacting worker engagement. Team members feel engaged as they converse emotionally with other team members who collaborate closely to accomplish particular tasks. Torrente, Salanova, Llorens and Schaufeli (2012) furthermore indicate that work engagement by a team mediates the impact of perceived social resources and team performance as assessed by the supervisor. Team members thus serve as models of engagement and performance and this implies that effective team functioning enhances worker engagement. Consequently, the following hypothesis was formulated:

- Hypothesis 5: Team effectiveness has a significant positive influence on the work engagement of CCRs.

According to Van den Broek, Barnes and Townsend (2008), most call centre operations organise their workforce around team structures; for example, $75 \%$ of Australian call centre operations are organised around team structures (p. 257). Making use of teams is also not a new concept in South African call centres. Wageman, Hackman and Lehman (2005) define team effectiveness more broadly by looking at the following three-dimensional conceptualisation:
- The productive output of the team (the product, service, or decision) must meet or exceed the standards of quantity, quality, and timeliness of the team's clients. It is the client's views that count, not those of team members. This is known as the process criteria of effectiveness and is a joint function of the following three performance processes (Wageman et al., 2005):

- the level of effort group members collectively expend carrying out task work,

- the appropriateness to the task of the performance strategies the group uses in its work, and

- the amount of knowledge and skill members bring to bear on the task.

Thus, teams that operate in ways that leave one or more of these three functions unfulfilled are likely to fall short of client standards of acceptable performance:

- The social processes that the team uses (in carrying out the work) should enhance members' capability to work together interdependently in the future.

- The group experience must contribute positively to the learning and well-being of individual team members rather than frustrate, alienate or de-skill members.

Specifically, Van den Broek et al. (2008, p. 258) conclude that 'teaming up provides ways for workers to develop coping mechanisms in order to survive the rigours of call centre work'. Teams can better provide a directed and collaborative effort to address complex task concerns (Montoya-Weiss, Massey \& Song, 2001) and to help workers through greater shared learning and problem-solving (Batt \& Appelbaum, in Kinnie et al., 2000), which will lead to higher productivity, greater levels of employee commitment and staff with more developed skills (Armistead et al., 2002). Hence, the sixth hypothesis was formulated:

- Hypothesis 6: Team effectiveness has a significant positive influence on CCRs' sense of coherence.

\section{Leadership effectiveness: A critical job resource in call centres}

Bakker and Demerouti (2007) report that a leader's appreciation and support can help workers to cope with job demands, facilitate their performance, and act as 'a protector against ill health' (p. 316). Van der Colff and Rothmann (2009) further advise that in order for employees to perceive that work expectations are manageable and within their power, employers should ensure that employees are equipped with the necessary knowledge, skills, material, instruments and other resources, and that the workload is balanced. 'Employees will regard their work as meaningful when a degree of independence and freedom of choice is allowed in the performance of their tasks. Participation in decision making will enhance employees' feeling of membership and contribute to the meaningfulness component of sense of coherence' (Van der Colff \& Rothmann, 2009, p. 8). Based on this rationale, the seventh hypothesis was formulated:

- Hypothesis 7: Leadership effectiveness has a significant positive influence on the sense of coherence of CCRs. 
Leadership is an important job resource predicting worker engagement. Kouzes and Posner (2001) report that leaders are at their personal best when displaying the following five practices of leadership:

- Challenging the process through innovative ways to improve the status quo, accepting inevitable risks as learning opportunities.

- Inspiring a shared vision by exciting others with their passionate belief in a better future.

- Enabling others to act by fostering collaboration, mutual respect, and a climate of trust and appreciation.

- Modelling the way by establishing principles and standards of excellence and then setting an example for others to emulate. They set interim goals so that people can achieve small wins as they work towards larger, more daunting objectives.

- Encouraging the heart by recognising individual contributions and involving individual members in celebrating achievements.

The Leadership Practices Inventory (LPI) was compiled to measure the above five leadership practices. Kouzes and Posner (2001, p. 5) note that the more frequently you demonstrate the behaviours included in the LPI, the more likely you will be seen as an effective leader' and that 'when people succeed in improving their use of the five leadership practices, they enhance their contributions to their organisations, their families and communities' (p. 2).

Research in call centres has shown that inadequate coaching and training and a lack of team leader support can contribute to job stress, depression, emotional exhaustion and anxiety (Bakker et al., 2003). Conversely, there is evidence of a positive relationship between three job resources (performance feedback, social support and supervisory coaching) and engagement, of which dedication is a core aspect. Hassan and Ahmed (2011) show that authentic leadership promotes subordinates' trust in a leader and also contributes to follower engagement. Also, Bakker and Xanthopoulou (2013) indicate that engaged leaders encourage the engagement and performance of followers through vicarious learning. Breevaart and Bakker (2013) mention that transformational leadership impacts positively on employee engagement but that some leadership styles can undermine motivation and well-being. Consequently, the following hypothesis was formulated:

- Hypothesis 8: Leadership effectiveness has a significant positive influence on work engagement.

People who frequently demonstrate leadership behaviours are seen as being more effective in meeting job-related demands, being more successful in representing their units to upper management, creating higher-performing teams and fostering loyalty and commitment (Kouzes \& Posner, 2001). If the team leader of a call centre is not effective in leading their team, there is a strong possibility that the team will not function effectively. Consequently, the following hypothesis was formulated:

- Hypothesis 9: Leadership effectiveness has a significant positive influence on the effectiveness of teams.

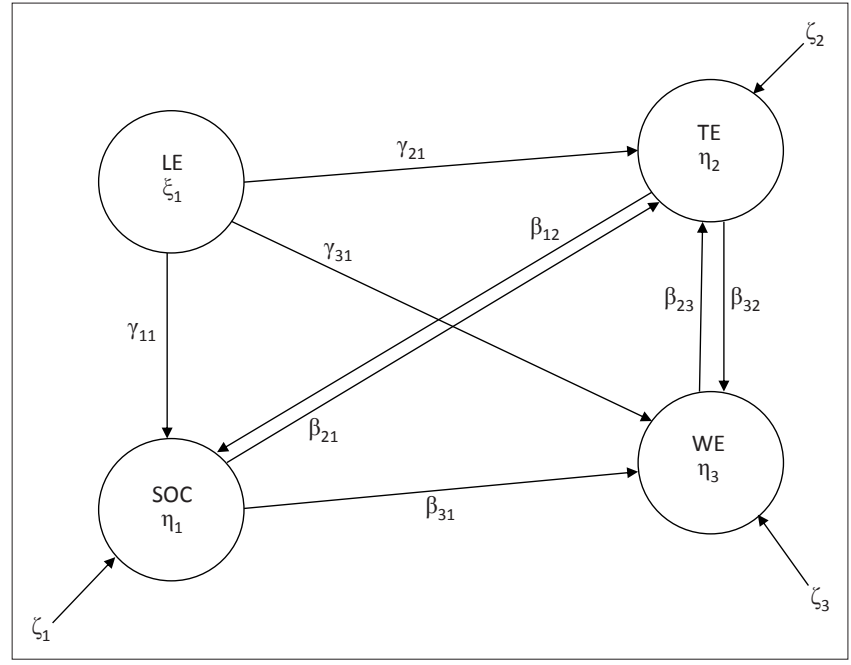

$\xi_{1}$, Leadership effectiveness; $\eta_{1}$, Sense of coherence; $\eta_{2}$, Team effectiveness; $\eta_{3}$, Work engagement. Note: It is assumed that the structural error terms are fixed to zero.

FIGURE 2: Proposed work engagement structural model.

\section{Proposed work engagement structural model}

Hypothesis 2 to Hypothesis 9 are graphically portrayed as causal paths in Figure 2.

\section{Method}

\section{Research approach}

A correlational, ex post facto, cross-sectional design was used with a survey as the data collection technique.

\section{Research method}

\section{Participants}

Employing convenience sampling, 14 call centres located across South Africa were approached to participate in the study. Of these, seven consented: three located in Cape Town, three in Pretoria and one in Johannesburg. The services offered by these call centres range from providing client support, selling services, products and insurance, providing technical and human resource support to internal personnel, offering telephonic support with regard to client or patient care, handling queries on disease and drug use, and providing emotional support and counselling.

The study population of 217 CCRs included 90 males (42\%), 122 females (56\%) and five respondents (2\%) who did not indicate their gender. The average age of the respondents was 29.2 years; the mean organisational tenure was 3.3 years, whilst the average period of serving in a team was 1.2 years. The racial demographics of the sample are: $39 \%$ White people, $33 \%$ Mixed race people, 24\% African people and 4\% Indian people. Thirty-five percent of the CCRs were from Pretoria, $50 \%$ from Cape Town and 15\% from Johannesburg.

\section{Measures}

Engagement (E): The shortened Utrecht Work Engagement Scale (UWES-9) was used. It consists of nine items and measures levels of engagement on a seven-point frequency rating scale, ranging from 0 (never) to 6 (every day) (Fourie, 
et al., 2008). It includes the three constituting aspects of work engagement: vigour, dedication and absorption. Vigour is assessed by three items that refer to high levels of energy and resilience. Dedication is assessed by three items that refer to deriving a sense of significance from one's work, feeling enthusiastic and proud about one's job, and feeling inspired and challenged by it. Absorption is also measured by three items, which refer to being totally and happily immersed in one's work and having difficulties detaching oneself from it so that time passes quickly and one is oblivious to one's surroundings.

Sense of Coherence (SOC): The 13-item short form (SOC13) of the Orientation to Life Questionnaire (OLQ) was used to measure sense of coherence. Strümpfer and De Bruin state that:

... researchers who wish to use a total SOC-score may use the short form, which is less than half the length of the long form, without much loss of information or accuracy $(2009$, p. 2).

The SOC-13 includes four items measuring meaningfulness, five items measuring comprehensibility and four items measuring manageability. Answers are given on a sevenpoint Likert scale on which the extreme answers (e.g. $1=$ never and $7=$ always) are formulated for each question (Fourie et al., 2008). A total score is summed, which can range from 13, which indicates a low sense of coherence, to 91, which indicates a high sense of coherence (Pallanta \& Laeb, 2002).

Leadership effectiveness (LE): (The kind permission granted by Barry Posner to use the Leadership Practices Inventory is hereby acknowledged.) Call centre representatives indicated how frequently their team leader engaged in each of 30 behaviours, six for each of the five leadership practices defined by Kouzes and Posner (2001). The inventory uses a 10-point frequency scale (where $1=$ almost never and $10=$ almost always).

Team effectiveness (TE): The Team Diagnostic Survey (TDS) is an instrument for assessing the properties of organisational work teams that has been specifically designed to be useful both in scholarly research on teams and in the practical diagnosis of teams' strengths and weaknesses (Wageman et al., 2005). When completed in full, the TDS generates a profile of the team.

For the purpose of this study only two sections (sections 8 and 9) of the TDS were used to measure team effectiveness. These two sections provide measures of the three effectiveness criteria. Section 8 comprises 13 statements; respondents rate the statements according to their accuracy in describing how members of the team work together. Each statement is marked on a five-point scale, where 1 is very inaccurate and 5 is very accurate. This section consists of four subscales, namely effort, performance strategy, knowledge and skill, and quality of interaction. Section 9 presents 13 statements about how respondents feel about their involvement with the team. Respondents indicate if they agree with each statement by allocating a point to each on a five-point scale, where $1=$ strongly disagree and $5=$ strongly agree. This section consists of four subscales, namely, relationship satisfaction, internal motivation, general satisfaction and growth satisfaction.

The Cronbach's alpha for measures are reported in Table 1 and Table 2.

\section{Research procedure}

A primary data design (data collected by the researcher) was followed to collect quantitative data (instrument scores) with a self-administered questionnaire. Preliminary, informal interviews were conducted with call centre managers and CCRs as a means of gaining insight into the nature of the call centre environment.

To make participation more attractive, each call centre could earn, by participating, a feedback file containing a feedback report and a collection of salient call centre articles and team-building activities; this incentive 'toolbox' was designed so that it would not sacrifice the anonymity, privacy or confidentiality of the respondents. An inclusion criterion was set that required the call centre to operate within a team structure and each team to be supervised by a team leader. A formal letter outlining the purpose of the study was provided to each call centre. Each participant in the study also signed an informed consent form that gave a comprehensive explanation of the study. Participation was voluntary. Anonymity and confidentiality were assured.

\section{Statistical analysis}

Data was captured using Microsoft Excel. Various statistical techniques were used to analyse the data and to test the proposed engagement model; these include computing Cronbach's alpha for testing reliability as part of the item analysis, Confirmatory Factor Analysis (CFA) for validating the measurement model, Exploratory Factor Analysis (EFA) where CFA indicated unsatisfactory model fit, Pearson

TABLE 1: Cronbach's alpha and average inter-item correlation for subscales.

\begin{tabular}{llcc}
\hline Subscales & Vigour & $\begin{array}{c}\text { Cronbach's } \\
\text { alpha }\end{array}$ & $\begin{array}{c}\text { Average inter- } \\
\text { item correlation }\end{array}$ \\
\hline Engagement (E) & Dedication & 0.85 & 0.67 \\
& Absorption & 0.85 & 0.68 \\
Sense of coherence (SOC) & Meaningfulness & 0.72 & 0.48 \\
& Comprehensibility & 0.58 & 0.26 \\
& Manageability & 0.71 & 0.28 \\
Leadership effectiveness (LE) & Challenging the process & 0.92 & 0.40 \\
& Inspiring vision & 0.94 & 0.74 \\
& Enabling others to act & 0.89 & 0.62 \\
& Modelling the way & 0.93 & 0.70 \\
& Encouraging the heart & 0.93 & 0.73 \\
Team effectiveness (TE) & Effort & 0.59 & 0.33 \\
& Performance strategy & 0.47 & 0.24 \\
& Knowledge and skill & 0.29 & 0.15 \\
& Quality of interaction & 0.67 & 0.34 \\
& Growth satisfaction & 0.48 & 0.27 \\
& Relationship satisfaction & 0.42 & 0.25 \\
& General satisfaction & 0.56 & 0.32 \\
& Internal motivation & 0.42 & 0.21 \\
\hline
\end{tabular}


correlations to test uni-variate relationships, regression analysis to test multivariate effects on engagement (E), and Structural Equation Modelling (SEM) path analysis. Finally, Partial Least Squares (PLS) path analysis was conducted as an alternative method for evaluating the structural model.

\section{Results \\ Measurement model}

\section{Item analysis}

An item analysis was done on all the items used in the questionnaire. The standard set for an acceptable reliability score is $\geq 0.6$ (Malhorta, 2004). From Table 1 it is evident that the Cronbach's alpha for the E subscales ranged from 0.72 to 0.85 and for the SOC items the alphas ranged from 0.58 to 0.71 . The LE subscales ranged between 0.89 and 0.94 . The alphas for E, SOC and LE are thus acceptable. The TE subscale alphas, however, did not fall within the acceptable range (from 0.29 to 0.67$)$. The inter-item correlations, however, showed to be positive for all the subscales of LE, E, SOC and TE.

\section{Evaluating the measurement model}

CFA was done on each subscale of E, SOC, LE and TE. The findings for the subscales of E, SOC and LE were satisfactory. However, the subscales of TE were found to be problematic. The data did not support the postulated subscales identified by Wageman et al. (2005) as contained in the TDS. An EFA was done to determine the number of factors in section $\mathrm{A}$ (effort, performance strategy, knowledge and skill, and quality of interaction) and section B (growth satisfaction, relationship satisfaction, general satisfaction and internal motivation) for TE.

Instead of four factors, two factors were extracted for section A: dedication and equity. Dedication refers to members of the team being committed; innovative; willing to share knowledge and expertise; learning from experience and being energised and uplifted by other team members. Item 3 and Item 6 did not match this new-found factor so they were removed. Equity refers to whether members do their fair share of work, noticing changes in the situation, the level of unpleasantness, how team members react when their actions are corrected and carrying out plans made to proceed with a task.

Two factors were extracted for section B: internal satisfaction and functional satisfaction. All of the items loaded onto either one of the two factors, thus no items were deleted. Internal satisfaction refers to learning a lot from the work, enjoying the work, feeling personal satisfaction if the team succeeds, feeling bad when the team performs poorly, enjoying working with team mates and getting to know them, advancing personal knowledge and skills and having personal satisfaction with the team. Functional satisfaction refers to relationships amongst team members, whether own creativity and initiative is suppressed by the team, whether working on the team is frustrating and whether own feelings are affected by team performance. Oblique rotation determined that the two factors were found not to correlate with each other, thus there was no shared variance between the two factors.

Item analysis for TE was repeated. The findings with the four new factors' subscales were acceptable (alpha ranging from 0.67 to 0.84 ). A confirmatory factor analysis was also repeated for TE and was found to be acceptable (RMSEA ranging from 0.048 to 0.074 ).

\section{Test of the work engagement structural model Fitting the structural model}

The model did not at first reflect in LISREL 8.8, possibly due to the small ratio between sample size and the number of parameters that had to be tested. The model was modified by removing the path coefficients not leading to engagement (see Figure 3 for the revised engagement structural model).

\section{Descriptive statistics and correlation analysis}

All correlations in Table 2 were found to be statistically significant at the $1 \%$ level. Although all the correlations were significant, two of them were weak correlations: SOC and LE $(r=0.19)$ and SOC and TE $(r=0.25)$. The Cronbach's alpha coefficients of all the instruments, that is the UWES-9, OLQ, LPI and TDS, are to be considered acceptable $(\mu \geq 0.70)$. Table 2 furthermore indicates significant positive relationships (statistically and practically) between work engagement, sense of coherence, leadership effectiveness and team effectiveness (all medium effects).

TABLE 2: Means, standard deviations, internal consistency reliabilities, and intercorrelations of study variables.

\begin{tabular}{lcccccc}
\hline Variable & M & SD & $\propto$ & E & SOC & LE \\
\hline Engagement (E) & 4.18 & 1.11 & 0.90 & - & - & - \\
Sense of coherence (SOC) & 4.67 & 1.05 & 0.80 & $0.42^{* \dagger}$ & - & - \\
Leadership effectiveness (LE) & 7.51 & 1.95 & 0.97 & $0.35^{* \dagger}$ & $0.19^{*}$ & - \\
Team effectiveness (TE) & 3.70 & 0.54 & 0.70 & $0.46^{*} \dagger$ & $0.25^{*}$ & $0.51^{*}$ \\
\hline
\end{tabular}

${ }^{*} p<0.01$, statistically significant.

$\dagger r>0.30$, practically significant (medium effect)

$\neq r>0.50$, practically significant (large effect).

$M$, mean; SD, standard deviation; E, engagement; SOC, Sense of coherence; LE, Leadership effectiveness; TE, Team effectiveness.

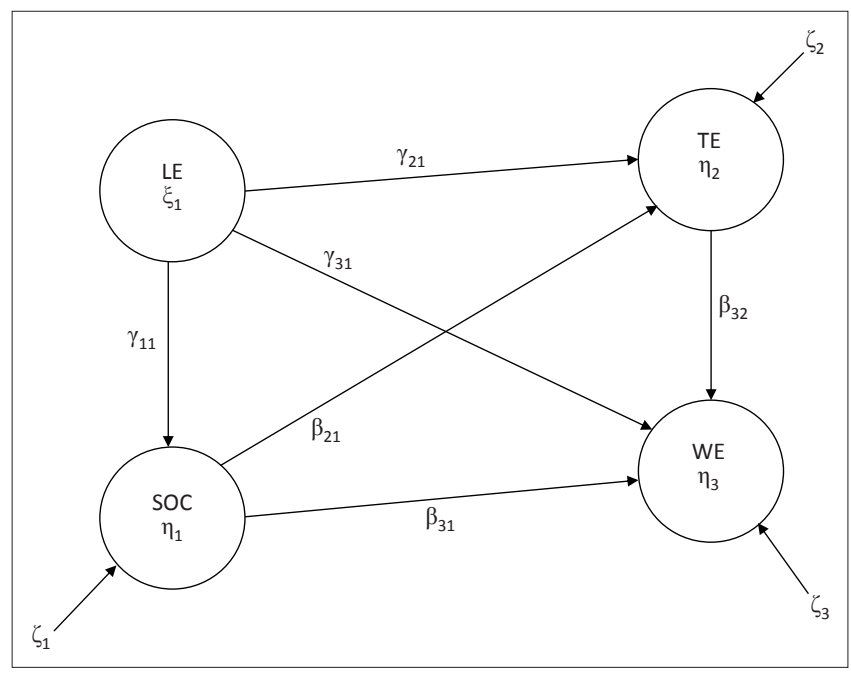

$\xi_{1}$, Leadership effectiveness; $\eta_{1}$, Sense of coherence; $\eta_{2}$, Team effectiveness; $\eta_{3}$, Work engagement. Note: It is assumed that the structural error terms are fixed to zero.

FIGURE 3: Revised work engagement structural model. 


\section{Multiple regression analysis}

A multiple regression analysis was conducted with work engagement as the dependent variable, and sense of coherence, leadership effectiveness and team effectiveness as independent variables. Table 3 indicates that $32 \%$ of the variance of work engagement in call centres is predicted by sense of coherence, leadership effectiveness and team effectiveness. The regression coefficients of all three variables were statistically significant, albeit marginal in the case of leadership effectiveness. The standardised regression coefficients for both sense of coherence $(B=0.32)$ and team effectiveness ( $(=0.31$ ) were moderate. CCRs seem to be more engaged in their work when they operate within an effective team and when they have a pervasive, enduring though dynamic feeling of confidence that the stimuli deriving from their internal and external environments in the course of living are structured, predictable and explicable; the resources are available to them to meet the demands posed by these stimuli; and these demands are challenges, worthy of investment and engagement.

\section{Partial least squares path analysis}

A PLS path analysis, a prediction-oriented structural equation modelling technique, was conducted to determine model fit. The outer-model measurement fit was found to be satisfactory, thus the subscale factors all measure what they are supposed to measure. Confidence intervals on the factor loadings were determined using bootstrap analysis. The path coefficients between LE, SOC, TE and E are depicted in Figure 4. All path coefficients in the model were found to be significant, except for the relationship between LE and E: the leadership practices of team leaders do not predict employee engagement in call centres. The nature of the work and other content and context factors in call centres more than satisfy the needs of CCRs, who seem to be indifferent to whether the team leader is effective or not.

In summary, Hypotheses 3, 4, 5, 7 and 9 are accepted. Hypothesis 8 should be rejected. Hypotheses 2 and 6 could not be tested due to model modification.

\section{Discussion}

The average level of engagement for the sample was 4.18. Schaufeli and Bakker (2003) compared the average level of work engagement between occupational groups. In their study farmers and managers exhibited the highest scores, whereas blue-collar workers and physicians showed the lowest scores. When comparing CCRs' levels of engagement (mean $=4.18$ ) with occupations scoring highest on engagement (farmers and managers, with average scores of 4.24 and 4.22 respectively), it appears that call centres are not in a crisis and thus are not the typical 'sweatshops' as reported in the literature; this necessitates the rejection of Hypothesis 1 .

The results of this study affirm the results of previous studies (Bakker \& Xanthopoulou, 2013; De Braine \& Roodt, 2011; Demerouti \& Bakker, 2011) and calls for the adoption of the
JD-R model to improve occupational health. According to this model the impact of job demands and job and personal resources on work engagement and performance can be investigated.

General practices should therefore be introduced to enhance the personal and job resources of employees. As 32\% of the variance in CCR work engagement is determined by SOC, TE and LE, a range of practices can be considered in order to enhance engagement, and ultimately performance, based on these three constructs:

- Minimise job demands like computer problems, changes in tasks, emotional demands and work overload.

- Give recognition; for example, have prize-giving events, award certificates and have a floating trophy for the year.

- Make the work environment fun; for example, have team building sessions with team development activities and celebrate successes.

- Involve CCRs in decision making by allocating portfolios, for example 'social member' to plan functions and 'finance member' to negotiate funds.

- Enhance career development and introduce succession planning. This will reduce intention to quit.

- Introduce formal training of team leaders by implementing a mentorship programme through which the team leader

TABLE 3: Regression analysis with work engagement as dependent variable.

\begin{tabular}{lccccc}
\hline Variable & $\mathbf{B}$ & $\mathrm{SE}$ & $\boldsymbol{t}$ & $\boldsymbol{p}$ & $\boldsymbol{R}^{\mathbf{2}}$ \\
\hline Intercept & - & - & -0.87 & 0.38 & 0.32 \\
LE & 0.13 & 0.07 & 1.96 & $0.05^{*}$ & - \\
SOC & 0.32 & 0.06 & 5.43 & $0.00^{* *}$ & - \\
TE & 0.31 & 0.07 & 4.62 & $0.00^{* *}$ & - \\
\hline
\end{tabular}

$\mathrm{LE}$, Leadership effectiveness; SOC, Sense of coherence; TE, Team effectiveness. ${ }^{*} p<0.05$.

$\beta$, beta; SE, standard error; $t$, t-test; $p, p$-value; $R^{2}$, coefficient of determination.

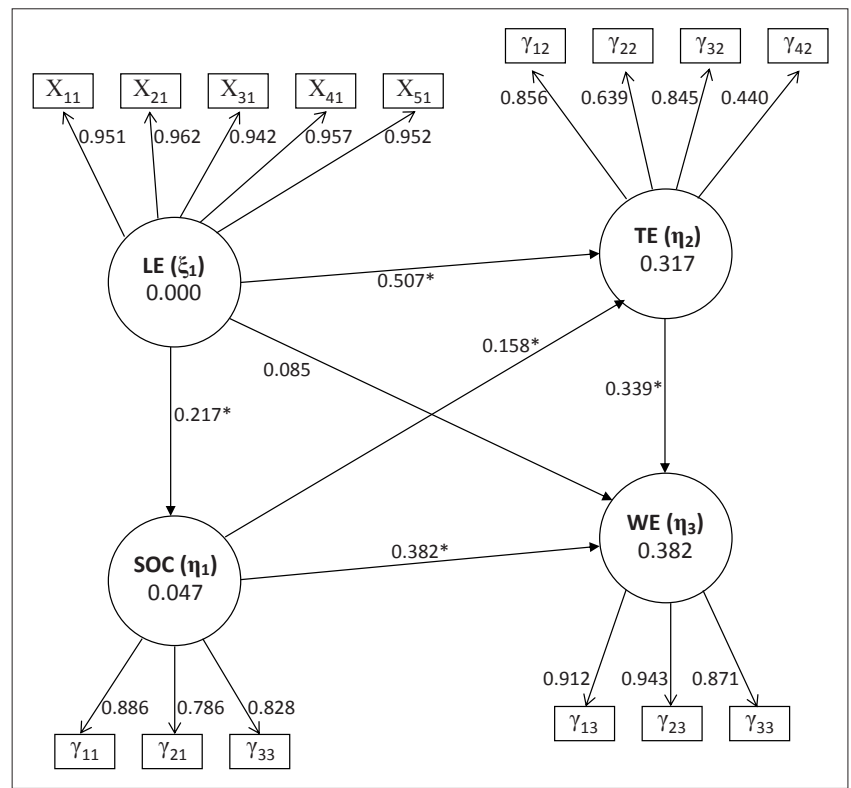

*, Significant path; $\xi_{1}$, Leadership effectiveness; $\eta_{1}$, Sense of coherence; $\eta_{2}$, Team effectiveness; $\eta_{3}$, Work engagement; $X_{11}$, Challenging the process; $X_{21}$ Inspiring vision; $X_{31}$, Enabling others to act; $X_{41}$, Modelling the way; $X_{51}$, Encouraging the heart; $\gamma_{11}$, Meaningfulness; $\gamma_{21}$ Comprehensibility; $\gamma_{31}$, Manageability; $\gamma_{12}$, Dedication; $\gamma_{22}$, Equity; $\gamma_{32}$, Internal satisfaction; $\gamma_{42}$, Functional satisfaction; $\gamma_{13^{3}}$, Vigour; $\gamma_{23^{\prime}}$, Dedication; $\gamma_{33^{\prime}}$, Absorption.

FIGURE 4: Partial least squares report for the work engagement model. 
is empowered with specified leadership practices and where constant development feedback is given.

- Implement a peer coaching system to provide ongoing feedback reports to team leaders and team members with regard to leader and member performance. This would enhance the understanding of job requirements.

- Make use of team building activities to encourage good teamwork and interpersonal relationships amongst colleagues and management. Individuals with a weak SOC should be assisted in dealing with distress they experience at work. Support, motivation and recognition from management and colleagues should be reinforced (Muller \& Rothmann, 2009, p. 9).

- Introduce discussion groups. This provides a collaborative effort to address complex task concerns aiding workers through greater shared learning and problem solving.

- Team leaders must practise support and active listening skills. A high quality relationship with a supervisor may alleviate the influence of job demands, since leaders' appreciation, motivation and support puts demands in another perspective.

- Introduce regular, structured team meetings. CCRs with a low SOC should be well informed about processes and procedures within the company (Muller \& Rothmann, 2009). Leaders can contribute to the development of employees' SOC by providing information in a consistent, structured, ordered and understandable format.

- Equip CCRs with the necessary knowledge, skills, material, instruments and resources, and ensure a balance in the load of tasks to be handled. CCRs should feel that the work expectations are manageable and within their power (Rothmann, Jackson \& Kruger, 2003).

- Let CCRs share in decision making; let teams come up with ideas to solve problems. Participation in decision making will enhance CCRs' feeling of membership and contribute to the meaningfulness component of SOC (Van der Colff \& Rothmann, 2009).

- Increase diversity in order to improve client service and general problem solving.

- Monitor team dynamics and try to have engaged members represented in all teams. The transference of engagement by role models enhances the collective engagement of a team.

- Practise good human resource management in terms of recruitment, selection, induction, training, compensation, health and safety, and industrial relations.

Tims et al. (2012) identify and laud the phenomenon of job crafting. Engaged and efficient employees will in most cases practise job crafting by altering task-related aspects of their jobs in order to attain personal and work-related goals. Job crafting comprises the changes introduced by employees in order to balance the job demands and personal resources with personal needs and abilities. This could involve initiating efforts to modify the nature of the relationships at work, for example the time spent with colleagues and customers, and also the intensity of these relationships. Employees may also craft the cognitions they have of aspects of the work in order to increase the meaning of working. It is not the same as job redesign where complete jobs are changed, but refers to smaller self-directed alterations. This practice should be encouraged by managers.

Particularly against the background of the positive metrics emerging regarding the call centre industry in South Africa, the dissemination of this psychometric data can fruitfully inform (potential) employees and managers online about current levels of occupational health and engagement as well as about relevant antecedent variables. Recommended guidelines can then serve to enhance the work functioning of call centre employees and teams. Examples of such wellness audits, currently being used in Spain and the Netherlands, can be found at www.wont.uji.es.

Future research should test whether other personal and job resources predict work engagement, for example psychological capital and the core job characteristics. Also, influence of the JD-R model on psychological and medical health symptoms should be investigated. The main shortcoming of the study was the use of a cross sectional approach to infer causality.

\section{Conclusion}

Contrary to the negative image attached to call centre jobs in the literature, results show a high level of work engagement for CCRs in the sample. Also, personal resources such as sense of coherence and job resources such as team effectiveness related significantly to work engagement. A non-significant relationship exists between leadership effectiveness and work engagement. This result reflects on the CCRs' diminished perception of the function and task of call centre managers. Managers are possibly viewed as administrators who do not provide job resources and who do not serve the needs of CCRs. Work engagement was best predicted by sense of coherence and then by team effectiveness.

\section{Acknowledgements Competing interest}

The authors declare that they have no financial or personal relationship(s) that may have inappropriately influenced them in writing this article.

\section{Authors' contributions}

B.B. (Stellenbosch University) was the project leader and cowrote the manuscript with M.B. (Stellenbosch University). Y.J.v.R. (Stellenbosch University) was responsible for the preliminary literature review, the survey and data processing. M.B. also made conceptual contributions and edited the manuscript.

\section{References}

Antonovsky, A. (1993). The structure and properties of the sense of coherence scale Social Science and Medicine, 36, 725-733. http://dx.doi.org/10.1016/0277-9536 (93) $90033-Z$

Armistead, C., Kiely, J., Hole, L., \& Prescot, J. (2002). An exploration of managerial issues in call centers. Managing Service Quality, 12(4), 246-256. http://dx.doi. org/10.1108/09604520210434857 
Bakker, A.B. (2011). An evidence-based model of work engagement. Current Directions in Psychological Science, 20(4), 265-269. http://dx.doi.org/10.1177/0963721411414534

Bakker, A.B., \& Demerouti, E. (2007). The Job Demands-Resources Model: State of the art. Journal of Managerial Psychology, 22(3), 309-328. http://dx.doi.org/10.1108/ 02683940710733115

Bakker, A.B., \& Demerouti, E. (2008). Towards a model of work engagement. Career Development International, 13(3), 209-223. http://dx.doi.org/10.1108/136204308 10870476

Bakker, A.B., Demerouti, E., Hakanen, J.J., \& Xanthopoulou, D. (2007). Job Resources boost work engagement, particularly when job demands are high. Journal of Educational Psychology, 99(2), 274-284. http://dx.doi.org/10.1037/0022-0663.99.2.274

Bakker, A.B., Demerouti, E., \& Schaufeli, W.B. (2003). Dual processes at work in a call centre: An application of the job demands-resources model. Europea Journal of Work and Organisational Psychology, 12(4), 393-417. http://dx.doi. org/10.1080/1359432034400016

Bakker, A.B., \& Xanthopoulou, D. (2013). Creativity and charisma among female leaders: the role of resources and work engagement. The International Journal of Human Resource Management, 24, 2760-2779. http://dx.doi.org/10.1080/09585192.20 12.751438

Banks, D., \& Roodt, G. (2011). The efficiency and quality dilemma: What drives South African call centre management performance indicators? SA Journal of Huma Resource Management, 9(1), 1-17. http://dx.doi.org/10.4102/sajhrm.v9i1.331

Baraka, H.A., Baraka, H.A., \& EL-Gamily, I.H. (in press). Assessing call centers' success: A validation of the DeLone and McLean model for information system. Egyptian Informatics Journal. http://dx.doi.org/10.1016/j.eij.2013.03.001

Benner, C., Lewis, C., \& Omar, R. (2007). The South African Call Centre Industry: A study of strategy, human resource practices and performance, Part of The Global Call Centre Industry Project, June.

Bond-Barnard, T.J., Steyn, H., \& Fabris-Rotelli, I. (2013). The impact of a call centre on communication in a programme and its projects. International Journal of Project Management, 31(7), 1006-1016. http://dx.doi.org/10.1016/j.ijproman.2012.12.012

Boonzaier, B., \& Boonzaier, M. (2008). From sweatshops to sweetshops - Job redesign as an innovation for sustaining call centres. Proceedings of the 16th International Conference on Pacific Basin Finance, Economics, Accounting and Management 02-04 July 2008 (pp. 229-253). Brisbane, Australia.

Brannan, M.J. (2005). Once more with feeling: ethnographic reflections on the mediation of tension in a small team of call centre workers. Gender, Work and Organization 12(5), 420-439. http://dx.doi.org/10.1111/j.1468-0432.2005.00282.x

Breevaart, K., \& Bakker, A.B. (2013). How leaders influence their followers' work engagement. European Work and Organizational Psychology in Practice, 5, 31-35.

Cartwright, S. (2003). New forms of work organization: Issues and challenges, Leadership \& Organization Development Journal, 24(3), 121-122. http://dx.doi.org/10.1108/ 01437730310469534

Crome, M. (1998). Call centres: Battery farming or free range. Industrial and Commercia Training, 30(4), 137-141. http://dx.doi.org/10.1108/00197859810218065

De Braine, R., \& Roodt, G. (2011). The Job Demands-Resources model as predictor of work identity and work engagement: A comparative analysis. SA Journal of Industrial Psychology, 37(2), Art. \#889, 11 pages. http://dx.doi.org/10.4102/sajip.v37i2.889

Demerouti, E., \& Bakker, A.B. (2011). The Job Demands-Resources model: Challenges for future research. SA Journal of Industrial Psychology, 37(2), Art. \#974, 9 pages. http://dx.doi.org/10.4102/sajip.v37i2.974

Demerouti, E., Bakker, A.B., Nachreiner, F., \& Schaufeli, W.B. (2001). The Job DemandsResources model of burnout. Journal of Applied Psychology, 86, 499-512. http:// dx.doi.org/10.1037/0021-9010.86.3.499, PMid:11419809

Ferreira, M. Jr., \& Saldiva, P.H.N. (2002). Computer-telephone interactive tasks: Predictors of musculoskeletal disorders according to work analysis and workers' perception. Applied Ergonomics, 33, 147-153. http://dx.doi.org/10.1016/S0003-6870(01)00058-8

Fisher, J., Milner, K., \& Chandraprakash, A. (2007). Organisational climate, job tension and job satisfaction in a South African call centre case study. Ergonomics SA, 19(2), 22-30.

Fourie, L., Rothmann, S., \& Van de Vijver, F.J.R. (2008). A model of work wellness for non-professional counsellors in South Africa. Stress and Health, 24, 35-47. http:// dx.doi.org/10.1002/smi.1163

Friginal, E. (2013). Evaluation of oral performance in outsourced call centres: An exploratory case study. English for Specific Purposes, 32(1), 25-35. http://dx.doi. org/10.1016/j.esp.2012.06.002

Gordi, M. (2006). Job Satisfaction Of Call Centre Representatives. Unpublished master's thesis, University of the Western Cape, Cape Town, South Africa.

Grebner, S., Semmer, N.K., Lo Faso, L., Gut, S., Kalin, W., \& Elfering, A. (2003). Working conditions, well-being, and job-related attitudes among call centre agents. European Journal of Work and Organizational Psychology, 12, 341-365. http://dx.doi. org/10.1080/13594320344000192

Hart, M.L., Chiang, Y-A.A., \& Tupochere, M. (2009). Balancing agent performance and customer service in contact centres. Journal of Contemporary Management, 6 , $151-169$.

Hassan, A., \& Ahmed, F. (2011). Authentic leadership, trust and work engagement World Academy of Science, Engineering and Technology, 56, 750-756.

Hauptfleisch, S., \& Uys, J.S. (2006). The experience of work in a call centre environment, SA Journal of Industrial Psychology, 32(2), 23-30. http://dx.doi.org/10.4102/sajip v32i 2.231

Holman, D. (2002). Employee well-being in calls centers. Human Resource Management Journal, 12(4), 35-50. http://dx.doi.org/10.1111/j.1748-8583.2002.tb00076.x
Holman, D.J. (2005). Call centres. In D.J. Holman, T.D. Wall, C.W. Clegg, P. Sparrow, \& A. Howard (Eds.), The essentials of the new work place: A guide to the human impact of modern working practices (pp. 111-131). Chichester: Wiley.

Holman, D., Batt, R., \& Holtgrewe, U. (2007). The Global Call Centre Report: International Perspectives on Management and Employment, Report on the global call centre network.

Kahn, W.A. (1990). Psychological conditions of personal engagement and disengagement at work. Academy of Management Journal, 33, 692-724. http://dx.doi.org/10.2307/ 256287

Kinman, G., \& Jones, F. (2003). Running up and down the escalator: Stressors and strains in UK academics. Quality in Higher Education, 9, 21-38. http://dx.doi.org/ 10.1080/13538320308162

Kinnie, N., Hutchinson, S., \& Purcell, J. (2000). 'Fun and surveillance': The paradox of high commitment management in call centers. The International Journal of Human Resource

Kouzes, J.M., \& Posner, B.Z. (2001). Leadership Practices Inventory [LPI]. (rev. 2nd edn.). (Electronic version). Participant's Workbook, Ph.D. San Francisco: Jossey-Bass/Pfeiffer.

Li, Y-H., Chen, C-Y., \& Lu, S-Y. (2008). Physical discomfort and psychosocial job stress among male and female operators at telecommunication call centers in Taiwan. Applied Ergonomics, 1-8.

Llorens, S., Bakker, A.B., Schaufeli, W., \& Salanova, M. (2006). Testing the robustness of the Job Demands-Resources Model. International Journal of Stress Management, 13(3), 378-391. http://dx.doi.org/10.1037/1072-5245.13.3.378

Lombard, A. (2009). Sensoray Intelligence in Call Centres. Paper presented at 3rd Annual Call Centre Conference, Johannesburg, South Africa.

Macey, W.H., \& Schneider, B. (2008). The meaning of work engagement. Industrial and Organisational Psychology, 1, 3-30. http://dx.doi.org/10.1111/j.1754-9434.2007.0002.x

Malhorta, N.K. (2004). Marketing research: An applied orientation. (4th edn.). Upper Saddle River, NJ: Pearson Education Inc.

Mauno, S., Kinnunen, U., \& Ruokolainen, M. (2006). Job demands and resources as antecedents of work engagement: A longitudinal study. Journal of Vocationa Behaviour, 70(1), 149-171. http://dx.doi.org/10.1016/j.jvb.2006.09.002

Mickan, S., \& Rodger, S. (2002). Characteristics of effective teams: A literature review. Australian Health Review, 23(3), 201-208. http://dx.doi.org/10.1071/AH000201

Montoya-Weiss, M.M., Massey, A.P., \& Song, M. (2001). Getting it together: Temporal coordination and conflict management in global virtual teams. Academy of Management Journal, 44(6), 1251-1262. http://dx.doi.org/10.2307/3069399

Muller, Y., \& Rothmann, S. (2009). Sense of coherence and employees' perceptions of helping and restraining factors in an organisation. SA Journal of Industrial Psychology, 35(1), 1-10.

Pallanta, J.F., \& Laeb, L. (2002). Sense of coherence, well-being, coping and personality factors: Further evaluation of the sense of coherence scale. Personality and Individual Differences, 33, 39-48. http://dx.doi.org/10.1016/S0191-8869(01)00134-9

Pech, R., \& Slade, B. (2006). Employee Disengagement: Is there evidence of a growing problem? Handbook of Business Strategy, 7(1), 21-25. http://dx.doi.org/10.1108/ 10775730610618585

Rameshbabu, A., Reddy, D.M., \& Fleming, R. (2013). Correlates of negative physical health in call center shift workers. Applied Ergonomics, 44, 350-354. http://dx.doi. org/10.1016/j.apergo.2012.09.002, PMid:23040668

Roberts, D.R., \& Davenport, T.O. (2002). Job engagement: Why it's important and how to improve it. Employment Relations Today, 29(3), 21-28. http://dx.doi.org/ 10.1002/ert.10048

Rose, E., \& Wright, G. (2005). Satisfaction and dimensions of control among call center customer service representatives. The International Journal of Human Resource Management, 16(1),136-160. http://dx.doi.org/10.1080/0958519042000295000

Rothmann, S., Jackson, L.T.B., \& Kruger, M.M. (2003). Burnout and job stress in a local government: the moderating effect of sense of coherence. SA Journal of Industria Psychology, 29(4), 52-60. http://dx.doi.org/10.4102/sajip.v29i4.122

Rothmann, S., \& Joubert, J.H.M. (2007). Job demands, job resources, burnout and work engagement of managers at a platinum mine in the North West Province. SA Journal of Business Management, 38(3), 49-61.

Salanova, M., Llorens, S., Cifre, E., Martinez, I., \& Schaufeli, W.B. (2003). Perceived collective efficacy, subjective well-being and task performance among electronic work groups: An experimental study. Small Groups Research, 34, 43-73. http:// dx.doi.org/10.1177/1046496402239577

Schaufeli, W., \& Bakker, A.B. (2003). Utrecht Work Engagement Scale Preliminary Manual (Electronic version 1, November 2003). Occupational Health Psychology Manual (Electronic version
Unit. PMCid:PMC1765719

Schaufeli, W.B., \& Bakker, A.B. (2004). Job demands, job resources and their relationship with burnout and engagement: A multiple-sample study. Journal of Organizational Behaviour, 25, 293-315. http://dx.doi.org/10.1002/job.248

Sonnetag, S. (2003). Recovery, work engagement, and proactive behaviour: A new look at the interface between non-work and work. Journal of Applied Psychology, 88, 518-528. http://dx.doi.org/10.1037/0021-9010.88.3.518

Straker, L., Abbott, R.A., Heiden, M., Mathiassen, S.E., \& Toomingas, A. (2013). Sitstand desks in call centres: Associations of use and ergonomics awareness with sedentary behavior. Applied Ergonomics, 44, 517-522. http://dx.doi.org/10.1016/j. apergo.2012.11.001, PMid:23218118

Strümpfer, D.J.W., \& De Bruin, G.P. (2009). Antonovsky's Sense of Coherence and Job Satisfaction: Meta-Analyses of South African data. SA Journal of Industrial Psychology, 35(1), 1-3.

Tims, M., Bakker, A.B., \& Derks, D. (2012). Development and validation of the job crafting scale. Journal of Vocational Behavior, 80, 173-186. http://dx.doi.org/ 10.1016/j.jvb.2011.05.009 
Torrente, P., Salanova, M., Llorens, S., \& Schaufeli, W.B. (2012). Teams make it work: How team work engagement mediates between social resources and performance in teams. Psicothema, 24(1), 106-112. PMid:22269372

Tracy, S.J. (2005). Locking Up Emotion: Moving Beyond Dissonance for Understanding Emotion Labor Discomfort. Communication Monographs, 72(3), 261-283. http:// dx.doi.org/10.1080/03637750500206474

Van den Broek, D., Barnes, A., \& Townsend, K. (2008). 'Teaming Up': Teams and Team Sharing in Call Centres. Journal of Industrial Relations, 50(2), 257-269. http://dx.doi. org/10.1177/0022185607087901
Van der Colff, J.J., \& Rothmann, S. (2009). Occupational stress, sense of coherence, coping, burnout and work engagement of registered nurses in South Africa. SA Journal of Industrial Psychology, 35(1), 1-10.

Wageman, R., Hackman, J.R., \& Lehman, E. (2005). Team Diagnostic Survey: Development of an Instrument. Journal of Applied Behavioral Science, 41, 373-398. http://dx.doi. org/10.1177/0021886305281984

Wallace, C.M., Eagleson, G., \& Waldersee, R. (2000). The sacrificial HR strategy in call centers. International Journal of Service Industry Management, 11(2), 174-180. http://dx.doi.org/10.1108/09564230010323741 